\title{
0 campo político da saúde do trabalhador e 0 Serviço Social
}

\section{The field of policies related to workers' health and Social Services}

\author{
Mônica Simone Pereira Olivar*
}

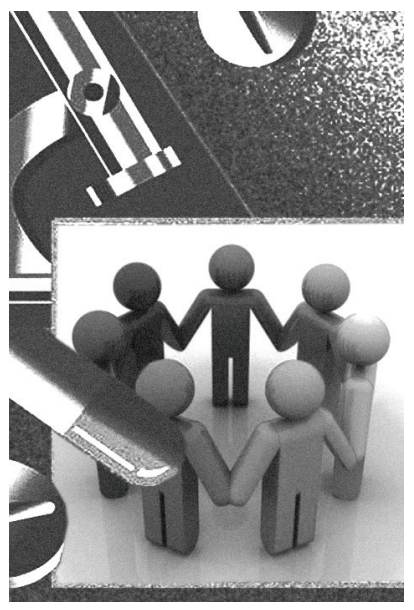

Resumo: Este artigo busca aproximar o debate político da saúde do trabalhador em articulação com o debate profissional do Serviço Social. Advinda de um processo constituinte com marcada participação dos movimentos social e sindical, a saúde do trabalhador passa a ter nova definição a partir da Constituição Federal de 1988, com a instituição do Sistema Único de Saúde e sua incorporação enquanto área de competência da saúde. Entretanto, caracteriza-se por limites em que o desafio está na compreensão da dinâmica capitalista e na ofensiva neoliberal.

Palavras-chave: Política de saúde. Saúde do trabalhador. Serviço Social.

\begin{abstract}
The article tries to approach the policy-related debate about workers' health articulated with the professional debate about Social Services. Resulting from a constituent process with marked participation of the social and union movements, the workers' health acquired a new definition from the 1988's Federal Constitution, in which the Unique Health System was institutionalized and incorporated as an area of health jurisdiction. However, it is characterized by limits in which the challenge is to understand the capitalist dynamics and the neoliberal offensive.
\end{abstract}

Keywords: Health policy. Workers' health. Social Services.

* Mestre em Serviço Social pela Uerj — Universidade do Estado do Rio de Janeiro, assistente social da UFRJ — Universidade Federal do Rio de Janeiro/RJ, Brasil. E-mail: msolivar@ig.com.br. 


\section{Introdução}

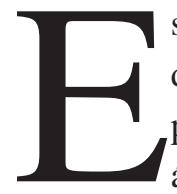

ste artigo se configura em uma análise aproximada do campo da saúde do trabalhador na conjuntura sociopolítica apresentada na atualidade, a partir de um balanço das principais iniciativas e estratégias, enquanto área de saúde pública, desencadeadas até aqui.

A priori se faz necessário evitar mal-entendidos que possam derivar do título deste artigo. O título sugestivo da saúde do trabalhador enquanto campo "político" parece elucidar ao leitor a afirmação de que o campo de saúde do trabalhador desmembra-se em componentes técnicos e políticos, como se fosse possível dissociar o campo (político) da saúde do trabalhador.

A saúde do trabalhador enquanto expressão concreta das contradições das relações sociais de produção, tal qual é concebida hoje no campo do conhecimento, não tem apenas uma direção técnica; ressalta-se o componente ético-político presente nos princípios do Sistema Único de Saúde (SUS) que norteiam as ações e ao mesmo tempo instrumentalizam os trabalhadores na efetivação por melhores condições de trabalho. Nesta ótica, na esteira de Gramsci, o campo da saúde do trabalhador é compreendido e concebido como produto de luta, complexo, diferenciado, contraditório, uma arena privilegiada onde os distintos sujeitos socais (trabalhadores, técnicos, gestores, empresários, sindicatos) se organizam, articulam as suas alianças, confrontam os seus projetos ético-políticos e disputam o predomínio hegemônico.

A mera referência indica duas hipóteses: a primeira, de que há um tecnicismo histórico da área da saúde do trabalhador elucidado em torno de normas e portarias interministeriais; a segunda, que a saúde do trabalhador auferiu um espaço, ainda que estreito, na arena política do governo de coalizão de Luiz Inácio Lula da Silva, concomitantemente com a suposta gestão democrático-popular apresentada nos primeiros quatro anos, de resto desmentida pela realidade. Ambígua é bem verdade, com feições ao mesmo tempo conservadora e progressista, como é seu governo.

Levando em conta o longo lapso de tempo entre a conformação legal enquanto política de Estado, pode-se afirmar que o atual governo, apesar do giro à direita (Netto, 2004; Braz, 2004) na condução da política macroeconômica, tem um papel central na retomada da atenção à saúde do trabalhador no Sistema Único de Saúde, como se verá adiante. 
O presente texto não tem outra pretensão que a de se somar ao debate atual sobre a saúde do trabalhador. Tal análise servirá para a articulação com um outro debate, também fecundo, que é a relação entre Serviço Social e saúde do trabalhador, tendo como parâmetro o projeto ético-político da profissão. Neste item surge a terceira hipótese de que o redimensionamento da área temática de saúde do trabalhador no Sistema Único de Saúde vem requisitando ao assistente social novas exigências, podendo constituir-se em um espaço de fortalecimento do projeto ético-político forjado pela profissão nos últimos trinta anos e, sobretudo, do Projeto de Reforma Sanitária.

\section{0 movimento histórico de construção do campo político da saúde do trabalhador no Brasil: breve análise}

A área de saúde do trabalhador tem uma profunda e visceral ligação com o pensamento de Karl Marx, desde a sua concepção até o desfecho da realização de seus objetivos no campo da execução das políticas públicas em saúde (Fadel de Vasconcelos, 2007).

Neste sentido, caem por terra as assertivas que nas décadas de 1980 e 1990 incidiram sobre os pilares das ideias e dos valores socialistas. Expressões como "fim do trabalho", "marxismo está morto", "adeus ao proletariado" foram colocadas em circulação pela direita e pela esquerda dita pós-moderna (Leher, 2007). Essas assertivas foram desmentidas pela realidade.

O conceito de saúde do trabalhador é carregado de historicidade, criticidade. Então, pensar em saúde do trabalhador significa trazer à tona dois referenciais fundamentais: a análise do processo de trabalho, a partir da acepção marxiana, e o trabalhador como ser social de intervenção desse processo em torno da luta pelo direito à saúde e condições de trabalho que não o agrida.

A expressão saúde do trabalhador, com a conotação de campo de conhecimentos, vinculado a uma área ou programa de saúde, é relativamente recente, podendo-se demarcar seu surgimento no final dos anos 1970, quando ela é recepcionada pelo discurso da saúde coletiva, especialmente após o início dos debates da reforma sanitária brasileira, influenciada pelo movimento da reforma sanitária italiana, de forte inspiração operária, e moldada nos pilares da medicina social latino-americana (Lacaz, 1997; Fadel de Vasconcelos, 2007). 
Até então, as referências técnico-científicas e político-institucionais sobre as questões da relação saúde-trabalho repousavam, exclusivamente, sobre os campos da Medicina do Trabalho e da Saúde Ocupacional, compreendida nesta última a própria Medicina do Trabalho e outros campos afins, como a Engenharia de Segurança, principalmente, e, por extensão, a Ergonomia, que também pode ser considerada campo de conhecimentos incluído no espectro da Saúde Ocupacional (idem).

De forma sintética, a novidade superante da saúde do trabalhador aos conceitos clássicos da medicina do trabalho e da saúde ocupacional — os campos tradicionais de atuação - ficou inicialmente por conta da incorporação de algumas variáveis que foram moldando uma nova categoria de análise. Dentre estas, Fadel de Vasconcelos (2007) destaca: a ampliação do objeto de intervenção sobre a produção stricto sensu (processos e ambientes de trabalho), incorporando outras variáveis sociais, econômicas etc.; a sujeição dos determinantes à capacidade de intervenção da saúde pública; a incorporação do trabalhador, enquanto sujeito e protagonista, ao desenvolvimento do campo de produção de conhecimentos e de intervenção; e, entre outras diferenças conceituais, a superação do limite contratual do trabalho como enfoque normativo de garantia da saúde no exercício cotidiano de trabalhar.

A Constituição Federal de 1988 determinou a incorporação do campo de saúde do trabalhador no âmbito do direito universal à saúde e competência do SUS (arts. 196 e 200 da Constituição Federal. A saúde do trabalhador também é citada em dez dispositivos da lei de concepção do Sistema Único de Saúde — SUS — Lei n. 8.080/90 e definida no art. $6^{\circ}$ dessa lei), inclusive as que são tradicionalmente de competência da área do trabalho, deixando à Previdência Social as atividades reguladoras do seguro social.

Com o advento do SUS e sua regulamentação por meio da Lei n. 8.080/90, fica claramente definido em seu artigo $6^{\circ}$ que a ele caberá atuar na saúde do trabalhador tanto na assistência, na vigilância e controle dos agravos à saúde relacionados ao trabalho, como na promoção da saúde, atribuições estas que, com a realização da II Conferência Nacional de Saúde do Trabalhador (CNST), em março de 1994, ficam politicamente mais bem demarcadas. Isto fica patente, na medida em que é aprovado, no relatório final, frise-se, com resistências de órgãos ligados ao Ministério do Trabalho, que o SUS deve ser a instância do Estado que deve coordenar e nuclear as ações voltadas para a promoção, a proteção e a recuperação da saúde dos trabalhadores (Brasil, MS, 1994). Assim, ao ser aprovada aquela delibe- 
ração/resolução na plenária de encerramento da II CNST, abria-se importante espaço para que o Ministério da Saúde (MS), por meio do SUS, assumisse um papel bem mais atuante para fazer cumprir aquela resolução (Lacaz, 2005).

Ao longo da década de 1990 constata-se que isto não ocorreu, inclusive dada a fragilidade orgânica do Ministério da Saúde no campo da saúde do trabalhador, o que levou o Ministério do Trabalho e Emprego a retomar a iniciativa nas ações para, sintomaticamente, baixar as portarias.

Do ponto de vista operacional, pode-se considerar que atualmente as ações em saúde do trabalhador são conduzidas pela área técnica de saúde do trabalhador do Ministério da Saúde - Cosat, situada no quarto escalão de poder da estrutura ministerial. Ou seja, pelo nível de sua inserção hierárquica na estrutura do Estado brasileiro, vê-se de pronto a sua incapacidade de estabelecer diretrizes com efetivo poder decisório (Fadel de Vasconcelos, 2007).

Até o ano de 2002 a estrutura do Ministério da Saúde comportava duas secretarias estratégicas: a Secretaria de Assistência à Saúde - SAS, com um enfoque regulador e financiador das ações da rede assistencial e um caráter operacionalizador da política, e a Secretaria de Políticas de Saúde - SPS, com um enfoque voltado para a formulação da política propriamente dita e um caráter implementador de ações programáticas, entre as quais a saúde do trabalhador, corporificada na Cosat (área técnica da saúde do trabalhador).

As duas secretarias confluíam em vários momentos para os mesmos objetos programáticos, mas não se comunicavam institucionalmente de forma sistemática no aprimoramento desses objetos. As (infrutíferas) tentativas de aproximação para consolidar a fratura institucional partiam, invariavelmente, da Cosat, considerada a legítima área programática de saúde do trabalhador, no Ministério da Saúde. Marchas e contramarchas estruturais, no âmbito do Ministério da Saúde, levaram a área de um lado para outro: Vigilância Sanitária, Assistência à Saúde, até se instalar na Secretaria de Políticas de Saúde — SPS, em 1998. No ano 2000, voltou a ser fragmentada com a criação de uma área paralela (Fadel de Vasconcelos, 2007).

Somente em 2003, no início do primeiro governo Lula, foi unificada sob a rubrica de Área Técnica de Saúde do Trabalhador — Cosat, vinculada à Secretaria de Atenção à Saúde - SAS.

Há um hiato de tempo muito grande entre uma determinação legal (Constituição Federal de 1988), que era um processo avançado, e a incorporação desta na estrutura do setor de saúde. Leia-se incorporação hierárquica institucional. 
Aqui cabe um esclarecimento, pois as ações de saúde do trabalhador historicamente já eram desenvolvidas por meio de um movimento político-ideológico que ficaria conhecido como os "Programas de Saúde dos Trabalhadores" (PSTs), com experiências que se desenvolveram particularmente em São Paulo, Minas Gerais, Rio de Janeiro, Bahia, Rio Grande do Sul, tanto no meio urbano como rural, a partir de 1984-85 (Lacaz, 1997), e a realidade refletida, além da imediaticidade, evidencia que tais ações eram mais progressistas do que as atuais.

No final dos anos 1990 e na década atual, a Área Técnica de saúde do trabalhador do Ministério da Saúde concentrou esforços em um amplo processo de capacitação técnica, para as ações de Vigilância e na Atenção Básica da Saúde; a elaboração de protocolos, ${ }^{1}$ normas e diretrizes, entre as quais, a Norma Operacional de Saúde do Trabalhador (Nost) em 1997; a lista de doenças relacionadas ao trabalho e о Manual de procedimentos para orientar as ações de saúde do trabalhador na rede de serviços de saúde, publicado em 2001; edição da Medida Provisória n. 316 , de 11 de agosto de 2006, que facilita o reconhecimento das doenças ocupacionais pelo INSS; o desenvolvimento de indicadores de saúde do trabalhador para os sistemas de informação em saúde e uma proposta de "Política Nacional de Saúde do Trabalhador", colocada em consulta pública, denominada Política Nacional de Segurança e Saúde do Trabalhador, disposta na Portaria Interministerial n. 800, de 3 de maio de 2005. Seu texto é a proposta oficial da política de governo, na atual conjuntura. ${ }^{2}$ Corrobora o fato de que a ressurreição da expressão "segurança do trabalho" demarca um evidente retrocesso conceitual do campo político da saúde do trabalhador.

Concretamente, pode-se afirmar que a hegemonia do marxismo no debate da saúde coletiva perdeu expressivo espaço (Matos, 2003), e esse giro conservador

1. Os protocolos de atenção à saúde do trabalhador têm o objetivo de homogeneizar e subsidiar diagnóstico, tratamento e vigilância, para os agravos de notificação compulsória — Portaria n. GM/MS777/04. São os seguintes: trabalho infantil, acidentes de trabalho, anamnese ocupacional, exposição a chumbo metálico, perda auditiva induzida por ruído, pneumoconioses, riscos químicos por exposição a benzeno, câncer relacionado ao trabalho - leucemias mieloide, dermatoses ocupacionais, exposição a material biológico.

2. Constitui-se em uma política de estado integrada em segurança e saúde do trabalhador. Para sua elaboração, foi constituído um GT Interministerial (Ministérios da Saúde, do Trabalho e Emprego e da Previdência Social), que elaborou documento de minuta de uma Política Nacional de Segurança e Saúde do Trabalhador, publicada para consulta pública até dezembro de 2005, por meio da Portaria Interministerial n.

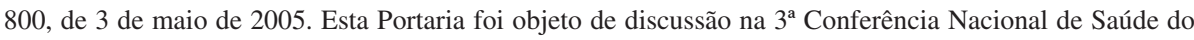
Trabalhador e, após receber contribuições, foi aprovada. 
ilustra os documentos técnicos concebidos em torno do campo de saúde do trabalhador. Se, historicamente, a área da saúde do trabalhador transitava no âmbito da saúde pública e coletiva de forma periférica, marginal, contra-hegemônica, envolta em uma indefinição institucional e da desfiliação recorrente que lhe foi imposta, aspectos que também contribuíram para o seu "enraizamento institucional tardio", hoje transita em meio a tensão entre o direito à saúde e a ofensiva neoliberal que vai debruçar a saúde pública.

\section{A saúde do trabalhador no governo Lula}

A saúde do trabalhador revela um momento de viabilização das conquistas obtidas no plano jurídico-institucional que abrangem direitos garantidos na legislação, mas que, na prática, ainda encontram dificuldade de sua efetivação, tendo em vista que esbarram no contexto da política neoliberal de desmonte do serviço público, assim como na conjuntura de retração do movimento organizado dos trabalhadores.

Apesar da consolidação do conceito de saúde como direito do cidadão e dever do Estado e das conquistas jurídico-institucionais (Constituição Federal de 1988 e Lei Orgânica da Saúde/Leis ns. 8.080/90 e 8.142/90), a política de saúde no Brasil, a partir dos anos 1990, passa por momentos distintos pós-Reforma Sanitária. Num primeiro momento, as proposições de saúde como direito social e o SUS (Sistema Único de Saúde) são questionados pela ideologia conservadora e, num segundo, aparecem propostas de normatizações visando consolidar a contrarreforma do Estado no âmbito das políticas sociais (Behring, 2003; Granemann, 2007) e, consequentemente, na saúde (Bravo, 2007).

A análise feita por diversos autores com relação ao governo de Luiz Inácio Lula da Silva é que se expressa não só a continuidade, mas o aprofundamento da orientação macroeconômica da era FHC (Braz, 2004; Netto, 2004; Bravo, 2004; Sader, 2004; Lesbaupin, 2003; Benjamim, 2003; Gonçalves, 2003).

Pode-se afirmar que as propostas e reformas defendidas pelo governo Lula após o seu primeiro governo dão sequência à contrarreforma do Estado iniciada na gestão de Fernando Henrique Cardoso (FHC), com uma diferença fundamental, conforme coloca Braz (2007) - tanto o primeiro governo Lula quanto o segundo desfrutam de um elemento que inexistia nos governos de FHC: uma ampla base 
política (mídia, parlamento, classe média, burguesia nacional e internacional, segmentos organizados da classe trabalhadora) empresta à contrarreforma tocada por Lula a marca da legitimidade popular. Principalmente porque a sua base política é deslocada e ampliada para os segmentos das classes mais pauperizadas ${ }^{3}$ por meio de programas compensatórios e de políticas sociais focalizadas, como o Bolsa Família, ${ }^{4}$ que foi o "carro-chefe" da sua primeira gestão e reeleição.

Ilustra esta assertiva o resultado de pesquisas de opinião sobre a popularidade de Lula no patamar de $80 \%$, apresentada pela mídia, em meio à crise de dimensão global que assola a cena econômica mundial desde setembro de $2008 .{ }^{5}$

A política de saúde é apresentada no programa de governo como direito fundamental e explicita-se o compromisso em garantir acesso universal, equânime e integral a ações e serviços de saúde. Entretanto, a concepção de seguridade social não é assumida, assim como, o projeto de reforma sanitária. Apresenta, pelo contrário, proposições que são contrárias ao projeto como a adoção de um novo modelo jurídico-institucional para a rede pública de hospitais: a criação de fundações estatais $^{6}$ (Bravo, 2007). Coaduna com o fato de que tanto no primeiro governo Lula

3. Tavares Soares (2004), ao analisar o programa social Fome Zero no início do governo Lula, ratifica que os programas sociais desse governo têm o propósito de selecionar "clientelas" por corte de renda baseado em "linhas de pobreza", promovendo um "cadastramento de pobres". Neste sentido, a focalização do gasto social nos "mais pobres" não apenas deixou de fora uma parcela dos "antigos" pobres, como, não incluiu os "novos pobres". De acordo com a mesma autora, os programas focalizados desse modo são a "antipolítica social", na medida em que exigem comprovação de pobreza — o que permite sua "inclusão" não por direito de cidadania, mas por ser mais "pobre" do que o vizinho.

4. O Bolsa Família é um programa de transferência que foi criado em 2003, com o desafio de combater a miséria e a exclusão social, por meio da unificação de todos os programas sociais (Bolsa-Escola, Bolsa-Alimentação, Cartão Alimentação [Fome Zero] e Auxílio-Gás) e a criação de um cadastro único de beneficiários.

5. A crise teve início no mercado imobiliário dos Estados Unidos. Com crédito farto e juros baixos, os imóveis do país sofreram alta valorização, causando refinanciamento de hipotecas. Para captar dinheiro, os bancos criaram um tipo de nota promissória, chamada título lastreado em hipotecas, e venderam para investidores que também passavam seus juros. Outras instituições tiveram problemas semelhantes, à beira de quebrar em meio à crise. E para ir contra a tendência de falência dos centros financeiros, o congresso dos EUA aprovou a intervenção do Estado, com plano de ajuda de US\$ 700 bilhões.

6. A proposição para a saúde é transformar os hospitais públicos em fundações estatais, onde o regime seria de direito privado; a contratação dos trabalhadores de saúde via CLT (acabando com o Regime Jurídico Único - RJU); o Plano de Cargos, Carreira e Salários seria por fundação (não considerando a luta por Plano de Cargo, Carreira e Salários dos trabalhadores do SUS); e o controle social seria substituído pelo conselho curador ou administrativo, conselho fiscal e conselho consultivo social. Este projeto foi rejeitado pelo Conselho Nacional de Saúde em reunião realizada em junho de 2007. 
quanto no segundo vem ocorrendo a redução do padrão de proteção social à assistência social, e o tripé inerente à seguridade social — saúde, previdência e assistência - é redimensionado em uma política focalista e seletiva.

Alguns gestores defendem que o SUS foi concebido enquanto sistema, e, assim sendo, constitui-se em eixo estruturador das políticas sociais e aglutinador de políticas públicas intersetoriais em todas as suas interfaces Estado-sociedade, entretanto, esta concepção abre margem a equívocos como vem acontecendo hoje com a implementação e gestão do Sistema Único de Assistência Social — SUAS (concebido também como sistema) em alguns municípios, reduzindo a seguridade social às políticas sociais setoriais. ${ }^{7}$

A consolidação da seguridade social é o resultado da unificação das políticas públicas, da formulação de uma política intersetorial e, sobretudo, da garantia da universalização e do acesso aos direitos, tais como aos serviços de promoção e prevenção à saúde, aos benefícios previdenciários e aos programas assistenciais.

A seguridade social brasileira instituída pela Constituição Federal de $1988^{8}$ está imbricada e condicionada pelo acesso ou exclusão a um emprego. Neste sentido, apesar de apresentar caráter inovador e pretender compor um sistema ou um padrão amplo de direitos sociais, acabou se caracterizando como um sistema híbrido, que conjuga direitos derivados e dependentes do trabalho (previdência) com direitos de caráter universal (saúde) e direitos seletivos (assistência) ${ }^{9}$ (Boschetti, 2004).

Assim se desenhou a história da saúde do trabalhador no Brasil. Um campo político tensionado por incompreensões e resistências intra e intersetoriais, ilustra-

O projeto de fundação estatal é também abordado no texto de Sara Granemann (2007). A autora analisa o projeto de fundação estatal como uma proposta de contrarreforma do Estado no âmbito das políticas sociais que afeta os interesses e os direitos dos trabalhadores e tem como fetiche a grande empresa.

7. Sobre este debate, vide o artigo de Rodrigues (2007).

8. Muito mais amplo que as conquistas registradas na Carta Magna de 1988, o conceito de seguridade social que fundamenta as reflexões e os posicionamentos políticos das entidades representativas da categoria (Enesso, Abepss, CFESS-Cress) compreende todos os direitos sociais previstos no art. $6^{\circ}$ da Constituição Federal (além do tripé assistência/saúde/previdência, a educação, trabalho, moradia, lazer e segurança) a serem assegurados por um sistema de proteção social que, superando a lógica contratualista do seguro social, avance na instituição de uma noção de cidadania com direitos amplos, universais e equânimes (Boschetti, 2004).

9. Importantes pesquisadores do tema conceituam a seguridade social de forma diferenciada: seguridade social tardia ou retardatária (Soares, 2000), inconclusa (Fleury, 2004), híbrida (Boschetti, 2004). 
do em um quadro institucional igualmente híbrido, constituído pelo Ministério do Trabalho e Emprego, Ministério da Previdência Social e Ministério da Saúde, revelando a fragmentação histórica em suas ações.

Não obstante o contexto histórico, hoje a atenção à saúde do trabalhador encontra-se inserida na agenda pública de discussão da política de saúde, conforme se verá a seguir.

\subsection{A Rede Nacional de Atenção Integral à Saúde do Trabalhador}

Em 2003, no início da gestão Lula, é concebida, no âmbito da Secretaria de Assistência do Ministério da Saúde, a área técnica de saúde do trabalhador denominada Cosat.

A Cosat tem como principal estratégia a reformulação e a implementação da Rede Nacional de Atenção Integral à Saúde do Trabalhador - Renast ${ }^{10}$ — como "estratégia de indução" à descentralização da contraditória Política Nacional de Segurança e saúde do trabalhador por meio da Portaria n. 1.679, de 19 de setembro de 2002, do Ministério da Saúde.

A Rede Nacional de Atenção Integral à Saúde do Trabalhador (Renast), consignada na Portaria n. 1.679, de 19 de setembro de 2002, e ampliada com a Portaria GM/MS n. 1.068, de 4 de julho de 2005, ambas emitidas pelo Ministério da Saúde, é composta pelos Centros de Referência em Saúde do Trabalhador ${ }^{11}$ - Cerest, serviços sentinelas de saúde do trabalhador ${ }^{12}$ e municípios sentinelas em saúde do

10. O processo de municipalização supõe a decisão municipal de aderir à política federal de saúde e, deste modo, obter o montante de recursos previstos para cada condição de gestão. Para tanto, é necessário adequar-se às normas federais. O Ministério da Saúde, através da Portaria n. 1.679, de 19 de setembro de 2002, incentiva a criação de centro de referência; para habilitação é preciso apresentar o Plano Estadual de Saúde do Trabalhador - Pest — com o objetivo de credenciar o estado na Rede Nacional de Atenção Integral à Saúde do Trabalhador — Renast — e habilitar-se a receber os recursos financeiros do Ministério da Saúde. Pela proposta de Brasília, cada município, de acordo com o seu perfil, é considerado A, B ou C. O centro estadual seria $\mathrm{C}$, e contaria com um repasse mensal de $\mathrm{R} \$ 40$ mil a $\mathrm{R} \$ 50$ mil para incentivo de implantação.

11. Nos últimos quatro anos, houve um crescimento do número de Centros de Referência em Saúde do Trabalhador (Cerest) habilitados, passando de 17 para 167.

12. A Rede Sentinela corresponde a serviços de assistência à saúde, indicados para executar procedimentos, diagnósticos, tratamento e notificação compulsória dos agravos à saúde relacionados ao trabalho. Atualmente foram habilitadas 836 unidades sentinelas. 
trabalhador e está organizada como rede nacional de informação e práticas de saúde por meio de ações assistenciais, de vigilância e promoção da saúde, nas linhas de cuidado da atenção básica, da média e alta complexidade ambulatorial, pré-hospitalar e hospitalar, sob o controle social, nos três níveis de gestão do SUS.

Apesar das críticas e dos desencontros institucionais observados no processo de elaboração desse instrumento, em particular a ênfase nas ações assistenciais, a portaria foi apoiada pelos profissionais e técnicos dos Cerests e setores do movimento dos trabalhadores, que reconheceram na iniciativa uma oportunidade de institucionalização e fortalecimento da saúde do trabalhador no SUS (Dias e Hoefel, 2005, p. 821). Pela primeira vez, seria possível contar com um financiamento extrateto das ações, vinculado à operacionalização de um plano de trabalho de saúde do trabalhador, em nível estadual e municipal.

Mas as divergências conceituais assinaladas não foram superadas, conforme sinaliza Fadel de Vasconcelos (2007). Ao contrário, observa-se que a Renast vem se consolidando cada vez mais como polo assistencial, razão pela qual corre o risco de consolidar seus centros como ambulatórios especializados.

De acordo como o mesmo autor, o foco assistencial das práticas, além de gerar um paralelismo com os equipamentos assistenciais já instalados, propicia que a rede se sinta desobrigada de prestar a assistência devida. Uma vez que exista um atendimento específico, os profissionais da rede tendem a encaminhar os trabalhadores para os Cerests, em especial no caso de acidentes de trabalho e doenças mais visivelmente relacionadas ao trabalho. Além disso, a sobrecarga de trabalho, trazida pela prática assistencial aos técnicos dos Cerests, sufoca a possibilidade de redirecionamento para atividades de planejamento, processamento de informações, vigilância, ensino, pesquisa e, principalmente, articulação intra e trans-setorial, em especial com as instâncias de controle social.

\subsection{Saúde do trabalhador e o Programa de Aceleração do Crescimento}

Reeleito em 2006, Lula marca o seu segundo governo combinando uma ação desenvolvimentista, com forte presença do Estado, resultando na criação de postos de trabalho e ampliação da teia de assistência por meio de um conjunto de medidas anunciadas em janeiro de 2007 que foram denominadas de PAC (Programa de Aceleração do Crescimento 2007-2010). 
O PAC se apresenta como uma política de governo cujo objetivo, a priori, é devolver ao Estado o seu protagonismo na dinamização da economia na garantia das condições estruturais para o crescimento econômico, pretendendo atingir vários núcleos do Estado, entre eles a saúde.

O PAC da Saúde ${ }^{13}$ pretende priorizar, em todos os eixos de intervenção, os objetivos e as metas do Pacto pela Saúde. ${ }^{14} \mathrm{O}$ programa prevê a melhoria do atendimento à saúde das crianças de zero a seis anos para reduzir, até 2011, em 5\% a taxa de mortalidade neonatal; ampliar de 27 mil para 40 mil as equipes de Saúde da Família em todo o país; prevê a volta dos médicos às escolas públicas; dar atenção especial à saúde dos homens; ampliação das farmácias populares para 500 unidades em todo o país; incentivar a produção nacional de medicamentos e equipamentos. Em relação à saúde do trabalhador, o PAC da Saúde tem como meta fortalecer a Rede Nacional de Saúde do Trabalhador. ${ }^{15}$

Portanto, a estratégia central do PAC na área temática de saúde do trabalhador no Sistema Único da Saúde continua reforçando a assistência em detrimento da vigilância, com a ampliação progressiva da rede assistencial de atendimento à saúde do trabalhador.

13. O presidente Luiz Inácio Lula da Silva lançou no ano de 2008 o PAC (Programa de Aceleração do Crescimento) da Saúde. O ministro da Saúde José Gomes Temporão apresentou um programa estruturado para ser cumprido até 2011, que vai consumir R \$ 90 bilhões; destes, R \$ 65 bilhões são das verbas já destinadas à saúde e R 24 bilhões provenientes da emenda 29, aprovada pela Câmara dos Deputados.

14. No final do primeiro mandato, foi apresentado o Pacto pela Saúde (2006) por meio da Portaria/GM n. 399 , de 22 de fevereiro de 2006, com o objetivo de rediscutir a organização e o funcionamento do SUS e avançar na implementação dos seus princípios. Corresponde a um pacto firmado entre os gestores do SUS, em suas três dimensões: pela vida, em defesa do SUS e de gestão. As prioridades do Pacto pela Vida são: saúde do idoso, mental, do trabalhador e da pessoa portadora de deficiência; controle do câncer de colo de útero e de mama; redução da mortalidade infantil e materna; fortalecimento da capacidade de resposta às emergências de saúde pública de relevância nacional e à ocorrência de doenças, com ênfase em dengue, hanseníase, tuberculose, malária e influenza, além da promoção da saúde e do fortalecimento da atenção básica. O governo tem incentivado a entrada dos municípios para o chamado pacto de gestão. Ao aderir, o município assume a plena gestão das ações de saúde. Assim, serviços que estavam a cargo dos estados migram para esses gestores, atendendo às demandas locais com mais eficiência. No país, 2.571 municípios aderiram ao pacto.

15. Pretende implantar, em 2011, 140 novos Centros de Referência em Saúde do Trabalhador, passando de 150 para 290, ao custo médio de R 50 mil para instalação e R \$ 30 mil mensais para manutenção; implantar, até 2011, 326 novos Serviços Sentinela em Saúde do Trabalhador, passando de quinhentos para 826, ao custo médio de R\$ 30 mil anuais; implantar, também até 2011, 163 Municípios Sentinela em Saúde do Trabalhador, ao custo de $\mathrm{R} \$ 10.000 /$ ano. 
No bojo de uma concepção ampliada de saúde do trabalhador podemos encontrar, nas raízes do seu contínuo recrudescimento, trabalhadores inseridos no mundo do trabalho, com a exposição crônica às mais diversas cargas de trabalho e subordinadas a esse contexto contemporâneo de grande vulnerabilidade, em que a convivência com o risco de perda do emprego, isto é, da sua condição objetiva de sobrevivência, faz parte do seu cotidiano.

A saúde do trabalhador se localiza em uma "zona de conflito" - em campo sensível da contradição entre o capital e o trabalho. Existem políticas de governo e de Estado que podem gerar agravos à saúde do trabalhador e políticas de governo e de Estado que acabam por ter que atender a esses agravos. ${ }^{16}$ Neste sentido, torna-se imperativo salientar a necessidade de resgatar e fortalecer o campo político da saúde do trabalhador, tendo a sua acepção enquanto espaço de conflito entre capital e trabalho, de expressão dos movimentos de pressão e resistência. Esse caráter político apresenta-se crucial na presente conjuntura.

\subsection{Conferências: o controle social democrático da saúde do trabalhador}

Além da Renast, destacou-se também no atual governo, em relação à saúde do trabalhador, a convocação da $3^{\text {a }}$ Conferência Nacional de Saúde do Trabalhador - $3^{\mathrm{a}}$ CNST - pelos três ministérios: Saúde, Trabalho e Emprego e Previdência Social por intermédio da Portaria Interministerial n. 774, de 28 de abril de 2004, alterada pela Portaria Interministerial n. 370, de 10 de março de 2005, e pela Portaria Interministerial n. 748, de 13 de maio de 2005. A conferência foi realizada no período de 24 a 27 de novembro de 2005, após onze anos da $2^{\text {a }}$ CNST, em Brasília, cujo tema central foi: "Trabalhar sim, adoecer não."

Em número de três, realizadas em 1986, 1994 e 2005, as conferências configuram-se em espaços estratégicos de formulação de propostas e locus do fazer político concebido, na acepção gramsciana, enquanto espaço contraditório e de conflitos, onde diferentes interesses estão em debate, contestação e disputa.

16. A luta pela proibição do amianto no Brasil é um exemplo deste fato. Quase cinquenta países baniram o amianto - toda União Europeia, Argentina, Uruguai, Chile, entre outros. Entretanto, no Brasil ainda não foi banido, graças ao lobby da indústria do amianto, que tem seus tentáculos nos sindicatos e no congresso. Usada principalmente na fabricação de telhas, caixas-d'água, forros, pisos, divisórias, a fibra do amianto é um dos mais importantes cancerígenos relacionados ao trabalho, segundo a OMS, responsável por cerca da metade das mortes por câncer profissional (Radis 29 e 69). 
O controle social-democrático ${ }^{17}$ se dá por meio de diversos mecanismos, como conselhos de políticas públicas e de direitos, plenárias temáticas, orçamento participativo, audiências públicas, Ministério Público, órgãos de defesa do consumidor, meios de comunicação, conselhos profissionais, plebiscitos, fóruns e conferências sobre essas políticas públicas (Bravo, 2001; Souza e Bravo, 2002).

A terceira conferência presidida pelo ministro de Estado da Saúde teve como objetivos propor diretrizes para efetivar a ação articulada dos órgãos setoriais do Estado na execução da política definida e para a ampliação e a efetivação do controle social. Neste sentido, o debate se deu em torno das três questões que constituem os três eixos orientadores da CNST: 1) Como garantir a integralidade e a transversalidade da ação do Estado em saúde dos trabalhadores? 2) Como incorporar a saúde dos trabalhadores nas políticas de desenvolvimentos sustentável no país? 3) Como efetivar e ampliar o controle social em saúde dos trabalhadores? (Brasil, Textos de apoio para a $3^{\text {a }}$ CNST, 2005).

A Conferência trouxe ao debate, por meio de seus textos de preparação, elementos conceituais contraditórios com feições regressivas que carecem de um debate fecundo. Ora, nada mais estranho ao espírito do SUS do que a concepção de saúde do trabalhador adstrito a categorias como "segurança do trabalho", "desenvolvimento sustentável", 18 "rede e municípios sentinelas".

Deve-se ressaltar que, neste contexto, ao adotar a expressão "Trabalhar sim, adoecer não" no tema central, de pronto retira-se a ênfase de uma política nacional direcionada à área, ao contrário das duas conferências anteriores. $\mathrm{O}$ foco na doença ("adoecer não") é de duvidosa interpretação para a sociedade, do ponto de vista da análise do modelo de organização dos processos produtivos. O binômio traba-

17. A categoria controle social foi, historicamente, entendida como controle do Estado ou do empresariado sobre as massas. Entretanto, o sentido de controle social inscrito na Constituição Federal é o da participação da população na elaboração, implementação e fiscalização das políticas sociais (Souza e Bravo, 2002).

18. O discurso do desenvolvimento sustentável esvazia conteúdos ideológicos historicamente consolidados, caso da luta de classes e da relação capital-trabalho. A ideia de sustentabilidade foi se consolidando como uma nova concepção de desenvolvimento, centrada fortemente nas variáveis ambientais, mas introduzindo variáveis de caráter econômico, social, político e ético. Um aspecto relevante é que o capital passa a se dividir conceitualmente em capital financeiro e capital social. Em outras palavras, na medida do aprofundamento das sociedades de mercado e de expansão mundial do capitalismo, o capital social vai, pouco a pouco, sendo incorporado ao próprio conceito de capital, mitigando o seu significado e a ideologia de exploração, acumulação e exclusão, para ganhar um novo significado simbólico de valorização humana. 
lho-doença, embora protagonista em sua relevância para a vida e a saúde dos trabalhadores, afunila, ainda que simbolicamente, e direciona para a medicalização da relação trabalho-saúde, cultura hegemônica de caráter antagônico ao da saúde do trabalhador (Fadel de Vasconcelos, 2007).

Coaduna-se com essa representação simbólica a utilização da expressão segurança no documento interministerial "Política Nacional de Segurança e Saúde do Trabalhador" que integra os textos de apoio para a $3^{\text {a }}$ CNST.

Entretanto, não obstante esse debate, é importante frisar que a $3^{\text {a }}$ Conferência Nacional de Saúde do Trabalhador possibilitou que o Controle Social refletisse sobre o mundo do trabalho e da saúde, com seus matizes regionais, e definisse 360 resoluções para seu enfrentamento. A conferência mobilizou cerca de cem mil pessoas do Brasil inteiro. Foram 1.241 encontros municipais e regionais realizados em todo país, no período de setembro a novembro de 2005. Os três dias da conferência nacional tiveram a participação de 1.380 delegados. Entre os participantes estavam usuários do SUS, associações, sindicatos, movimentos populares, trabalhadores informais e profissionais da saúde, fiscais do trabalho e peritos da previdência. $O$ principal avanço da conferência é ter tido a chance de discutir com diversos setores da sociedade que antes não haviam se incluído nesse processo de saúde do trabalhador, como, por exemplo, as associações de moradores.

Concluída a Conferência, iniciou-se processo de devolução das deliberações da $3^{\text {a }}$ CNST, atendendo à Resolução n. 300 (Eixo temático 3: participação da comunidade na gestão em saúde do trabalhador), que determina: "Garantir a efetivação das propostas aprovadas nas conferências de saúde do trabalhador, de um modo geral, por meio de plenárias estaduais de acompanhamento, retornando o relatório final para as suas bases representativas, monitorando o cumprimento das propostas aprovadas, sendo enviada para o endereço de cada delegado participante, cópia do texto final."

A partir da deliberação 300 da $3^{\text {a }}$ CNST surgiu a proposta da Rede Escola Continental em Saúde do Trabalhador, que foi apresentada a vários países da América do Sul no Fórum Social Mundial realizado em Caracas/Venezuela em fevereiro de 2006. ${ }^{19}$ Como desdobramentos ocorreram, no Brasil, duas reuniões suscitadas

19. Em 2006, pela primeira vez, o Fórum Social Mundial foi policêntrico, ocorrendo edições na América (Caracas, Venezuela), Ásia (Karachi, Paquistão) e África (Mabako, Mali). O Fórum de Caracas foi o mais permeável à militância socialista ligada a sindicatos, partidos e movimentos sociais anticapitalistas e teve 
pela Área Técnica de saúde do trabalhador — Cosat —, no sentido de identificar as instituições, organizações não governamentais, sindicatos, centrais e diversos atores que desenvolvem formação em saúde e, desta forma, reunir experiências, sugestões e abordagens diversas para a capacitação em massa de trabalhadores e dos movimentos sociais.

Assim, se por um lado o Controle Social em Saúde do Trabalhador tem uma história que é anterior à existência do próprio SUS e deve, por isso, ser considerado no sentido de valorizar esta trajetória e especificidade, por outro a realização de conferências no formato em que vêm sendo feitas e por temáticas específicas deve ser repensada, na medida em que a fragmentação de temas não contribui para a reflexão sobre os destinos do SUS num momento em que a focalização das políticas sociais ganha mais força. Diante desse dilema, devemos caminhar para a realização das conferências nacionais de saúde, nas quais as temáticas específicas sejam embutidas, na perspectiva de sua contribuição para a construção do SUS como um todo a ser cada vez mais aperfeiçoado e defendido, na medida em que se configura como a única política de bem-estar social que logramos criar com nossas lutas, embates e que remontam ao Movimento da Reforma Sanitária (Lacaz, 2005).

\section{Serviço Social e saúde do trabalhador}

A saúde do trabalhador e o Serviço Social possuem alguns traços comuns, conforme sinaliza Freire (1998). Entre esses traços frisa-se que eles desenvolvem, ao mesmo tempo, uma notável renovação a partir dos anos 1960, consolidada e indiscutível nos anos 1980, na América Latina. Nesse período, essas áreas iniciaram uma interlocução com as ciências sociais, adotando uma perspectiva crítica, sob influência do materialismo histórico, inserindo a análise de seus objetos na totalidade econômica, política e social. Ao mesmo tempo, sobretudo nos anos 1990, ambos também sofrem, no Brasil, os impactos negativos do processo de reestruturação produtiva e o neoliberalismo.

uma posição central, não apenas por ser o locus para o qual convergiram os movimentos latino-americanos, mas por seu caráter explicitamente anti-imperialista e pelas polêmicas que as complexas relações entre governo e fórum produziram pela presença marcante de Hugo Chávez (presidente da Venezuela) (Leher, 2007). 
Ao dialogar sobre o Serviço Social e a saúde do trabalhador faz-se mister ter em mente a premissa de que a intervenção profissional é condicionada por determinantes sócio-históricos e, institucionais e ao mesmo tempo, por repostas profissionais vinculadas aos projetos coletivos.

Isto quer dizer que hoje, em face do projeto societário delineado pelo capital, o Serviço Social é convocado a adequar-se ao novo cenário sob a hegemonia das finanças e seu fetiche (Iamamoto, 2007) e a exaurir-se em novos espaços sócio-ocupacionais produto dessas transformações societárias, bem como responder às demandas do mercado de trabalho, à assistencialização e ao tratamento terapêutico.

Como também, em face dos princípios do projeto profissional que acompanhou a curva ascendente do movimento democrático e popular culminando com a Constituição de 1988 e a descentralização das políticas sociais, o Serviço Social vem se apropriando de outros novos espaços sócio-ocupacionais, como os conselhos de políticas e de direitos.

Desta forma, a categoria desenvolve suas atividades em condições e relações de trabalho concretas e dinâmicas, tendo como respaldo a legislação profissional e os fundamentos construídos na formação e no aprimoramento permanente.

Portanto, o trabalho dos assistentes sociais não se desenvolve independentemente das circunstâncias históricas e sociais que o determinam de fato. A inserção do Serviço Social nos diversos processos de trabalho encontra-se profunda e particularmente enraizada na forma como a sociedade brasileira e os estabelecimentos empregadores do Serviço Social recortam e fragmentam as próprias necessidades do ser social e, a partir desse processo, como organizam seus objetivos institucionais que se voltam para a intervenção sobre essas necessidades (Abepss, 1996). Em relação ao campo da saúde do trabalhador, é tensionado entre as demandas coletivas dos usuários (seja nos serviços públicos de saúde, seja nos serviços assistenciais das empresas) e as demandas das classes proprietárias e exploradoras do capital financeiro.

A não consideração desse processo de subordinação, aliada a uma frágil discussão, constituem uma das variáveis que interferem na tensão existente entre as exigências do mercado e a idealização dos profissionais acerca de suas ações profissionais (Costa, 2000).

Conforme colocado inicialmente, o redimensionamento no campo da saúde do trabalhador vem requisitando do assistente social novas exigências e é fruto do trânsito, como afirma Netto (1992), da atuação profissional exclusiva- 
mente pautada na execução terminal das políticas sociais para uma atuação profissional competente na gestão da totalidade do processo da política social (Matos, 2006).

As novas demandas colocadas - gestão, assessoria e a pesquisa como transversal ao trabalho profissional que estão explicitadas na Lei de Regulamentação da Profissão (1993) e nas Diretrizes Curriculares, aprovadas pela Abepss (1996) — são exemplos das exigências de atuação do assistente social na área de saúde do trabalhador que surgiram com o processo de descentralização das políticas públicas sociais.

O campo da saúde do trabalhador, pela sua natureza multidimensional e seu caráter interdisciplinar, vem demarcando diferentes espaços sócio-ocupacionais para o Serviço Social. O profissional é requisitado em diferentes serviços e programas, como: atenção básica à saúde; em centros de referência em saúde do trabalhador, em hospitais gerais e de emergência e nos serviços referenciados; na área de reabilitação profissional previdenciária e/ou organizações privadas ou públicas; em serviços de saúde e segurança do trabalho vinculados a empresas e instituições, bem como na gestão de recursos humanos para o desenvolvimento de programas voltados para a saúde do trabalhador; em sindicatos que desenvolvem programas de promoção à saúde; nos serviços de vigilância e educação em saúde; nas comissões de saúde do trabalhador; em trabalhos de assessoria e consultoria; em organizações de ensino e pesquisa em saúde (Mendes e Wünsch, 2008).

Historicamente, os assistentes sociais dedicaram-se à implementação de políticas públicas, localizando-se na linha de frente das relações entre população e instituição (Iamamoto, 2007). Embora ainda esse seja o perfil predominante, dada a ênfase no caráter assistencial da rede de atendimento, não é mais o exclusivo, sendo abertas outras possibilidades.

Os assistentes sociais que se inserem na área temática da saúde do trabalhador no Sistema Único de Saúde são chamados a atuar, no tempo presente, na esfera de gestão e planejamento, ampliando seu espaço ocupacional para atividades relacionadas ao controle social, à implantação e orientação de conselhos gestores, à capacitação de conselheiros e à assessoria às equipes de saúde das chamadas "redes sentinelas" na sensibilização para a atenção aos acidentes de trabalho nas emergências públicas de saúde, somando-se às atividades tradicionais demandadas historicamente, como a assistência e a tão decantada em debate da saúde coletiva, que é a questão do acolhimento individual ao trabalhador. 
A questão do modelo assistencial é um dos pontos nevrálgicos do debate estrutural da área. Embora esse fosse o retrato da realidade na década de 1990, ainda hoje, com o "reordenamento" do modelo, com institucionalização da Renast — Rede de Atenção Integral à Saúde do Trabalhador, o problema não foi resolvido, tendo se cristalizado ainda mais.

O assistente social, potencialmente, tanto pode contribuir para reforçar a alienação - no avesso do seu discurso humanista tradicional —, como também para elucidar e desencadear mediações em relação a situações e processos sociais, no sentido do seu entendimento mais amplo — no local de trabalho e na sociedade — e na direção do enfrentamento das contradições, expressas na realidade cotidiana, posição que Freire (2003) denomina "avesso do avesso".

O Projeto Ético-Político hegemônico junto à categoria profissional e consolidado na década de 1990, garantido inclusive nos aparatos jurídico-legais que o subsidia, como o Código de Ética Profissional de 1993, a Lei de Regulamentação da Profissão e as Diretrizes Curriculares, está diametralmente em posição contrária ao projeto societário em vigência - o que obstaculiza o fortalecimento do projeto profissional em questão, favorecendo e estimulando a configuração de tantos outros. Daí o reconhecimento que não há um único projeto profissional, e que estes estão sempre em disputa, embora em determinado momento histórico um deles se configure hegemônico, isto é, capaz de conferir à categoria profissional determinada direção social e política (Ortiz, 2007; Netto, 2005).

Em outras palavras, pode-se conceber o trabalho no campo da saúde do trabalhador como desmistificador da alienação junto aos profissionais da rede, e assim se inserir enquanto profissional, na medida de sua capacidade de fazer mediações com o coletivo de trabalhadores, sinalizando para a capacidade de intervenção sobre os processos determinantes dos problemas, buscando, enfim, o "avesso do avesso". Ou na contramão e antagonicamente ao reclamado pelo projeto profissional atual, inserir-se nesse novo espaço sócio-ocupacional enquanto agente funcional a um Estado assistencialista, com uma intervenção imediatista frente às expressões da questão social, trabalhando com a individualização do acolhimento, disfarçado de atendimento social, psicológico e médico, mantendo a invisibilidade do processo produtivo que alija esse trabalhador.

Considerando que, por meio da apreensão do referencial teórico-metodológico, ético-político, investigativo e técnico-operativo, o assistente social tem a exigência de moldar o trabalho profissional com vistas a um trabalho consciente, 
crítico, não subalterno, direcionado aos interesses e às necessidades dos usuários, e não subordinado aos rearranjos propostos pelo Estado neoliberal que vem ao longo dos anos descaracterizando a proposta original do SUS contido no projeto de Reforma Sanitária.

\section{Considerações finais: limites e desafios}

O panorama da saúde do trabalhador configurado na contemporaneidade, despretensiosamente traçado aqui, traz algumas indagações. A partir do que foi discutido, é possível alinhar algumas considerações, sem a pretensão de fazer uma avaliação conclusiva.

A atenção à saúde do trabalhador é operacionalizada, na atual conjuntura, pela implementação da Renast - Rede Nacional de Atenção Integral à Saúde do Trabalhador, concretizada no esforço atual de estruturação do seu eixo estratégico: a rede nacional do Cerest - Centro de Referência em Saúde do Trabalhador.

Entretanto, é importante pontuar alguns embates e enfrentamentos no que se refere à saúde do trabalhador na atualidade.

Hoje, na saúde, dois polos se contrapõem — o Projeto de Reforma Sanitária e o Projeto Privatista (Bravo e Matos, 2001). O atual governo ora fortalece o primeiro projeto, ora mantém a focalização e o desfinanciamento, características do segundo projeto (Bravo e Matos, 2004).

Nota-se que a saúde do trabalhador não foi estabelecida como prioridade no Pacto Gestão, proposto pelo Ministério da Saúde — que norteará, daqui para a frente, o processo de implementação do SUS, em todo o território nacional —, e isto, em um contexto de estruturação ainda incipiente da Renast. Apesar de, reconhecidamente, a Cosat ter se ampliado e se fortalecido na atual gestão - concomitantemente com a atual gestão democrático-popular do governo federal —, ela não acumulou suficiente força para superar a fragilidade institucional histórica que moldou seu processo de desenvolvimento.

Percebe-se, nessa conjuntura, a "fragilidade institucional histórica" da Cosat; a dispersão e insuficiente articulação, em nível nacional, dos sindicatos de trabalhadores, das organizações de trabalhadores e demais movimentos sociais interessados por este problema, e a "refratariedade institucional", manifesta em todos os níveis de gestão do SUS, em incorporar a saúde do trabalhador na sua agenda. 
Evidencia-se o enfraquecimento e a pouca capacidade de pressão dos trabalhadores da saúde, sindicatos, movimentos sociais, identificando a falta de qualificação das demandas, diante dos desafios apontados pelo processo de contrarreforma na saúde pública.

Constata-se que a ausência de um foco para a descentralização das ações no Estado criou um vazio no campo da saúde do trabalhador, pois nunca houve prioridade para este campo por parte do setor da saúde.

Nas ações, predomina a dicotomia entre preventivo/assistencial, sendo historicamente constatável por meio da fragmentação das ações em sua competência institucional, cabendo aos Ministérios da Saúde e da Previdência Social as ações assistenciais e exclusivamente ao Ministério do Trabalho e Emprego as ações de fiscalizações dos ambientes de trabalho.

Destaca-se a pouca visibilidade dos acidentes e doenças relacionadas ao trabalho, especialmente no que diz respeito à falta de dados, sendo este um problema histórico e que se inscreve no rol de prioridades da Renast, materializada na notificação compulsória dos agravos à saúde dos trabalhadores, conforme a publicação da Portaria n. 777, de 28 de abril de 2004, e do sistema de informação Sinan-NET, mas que ainda não foi aderido pelos serviços e gestão da saúde como deveria.

Percebe-se uma brutal diferença entre os números oficiais e os reais de acidente de trabalho. Servidores públicos e trabalhadores informais que somam cerca de $50 \%$ da população ocupada não entram nas estatísticas oficiais de acidentes e doenças do trabalho em virtude da lógica financeira de notificação. Como só as empresas pagam o Seguro de Acidente de Trabalho (SAT), apenas os trabalhadores celetistas entram nas estatísticas da Previdência e do Ministério do Trabalho.

Neste cenário, considera-se fundamental a defesa das propostas do Projeto de Reforma Sanitária construído nos anos de 1980 e a mobilização e luta dos movimentos sociais. A saúde do trabalhador se inscreve no âmbito da participação e cogestão das políticas públicas. Cabe frisar que é importante coletivizar a questão trabalho e saúde para superar as atividades técnico-burocráticas e estruturar ações técnico-políticas. É preciso resgatar o campo político da saúde do trabalhador, tendo a clareza de que a saúde do trabalhador é a expressão concreta das relações sociais (Freire, 1998) e de que o recrudescimento das condições de trabalho, o qual atinge o trabalhador, é uma das expressões da questão social que constitui a matéria-prima ou objeto do trabalho profissional do assistente social. 
Todavia, sendo a profissão atravessada por relações de poder, dispõe de um caráter essencialmente político, o que não decorre apenas das intenções pessoais do assistente social, mas também dos condicionantes histórico-sociais dos contextos em que se insere e atua (Iamamoto, 2007). Tal direção social, aliada ao amadurecimento teórico da profissão, vem contribuir para a reflexão crítica e o desvelamento da realidade social em suas diferentes expressões neste campo político e o espraiamento de novos espaços sócio-ocupacionais na contramão da lógica financeira neoliberal.

Artigo recebido em abr./2009 aprovado em mar./2010

\section{Referências bibliográficas}

ABEPSS. Proposta básica para o projeto de formação profissional: novos subsídios para o debate. Serviço Social \& Sociedade, São Paulo, n. 50, 1996.

BEHRING, Elaine Rossetti. Brasil em contrarreforma: desestruturação do Estado e perda de direitos. São Paulo: Cortez, 2003.

BENJAMIM, César. Economia brasileira e política econômica. Praia Vermelha: estudos de política e teoria social. Rio de Janeiro, 2003.

BOSCHETTI, Ivanete. Seguridade social e projeto ético-político do Serviço Social: que direitos para qual cidadania? Serviço Social \& Sociedade, São Paulo, n. 79, 2004.

BRASIL. Constituição (1988). Constituição da República Federativa do Brasil. Brasília: Senado, 1988.

. Ministério da Saúde. Lei Orgânica da Saúde n. 8.080, de 19 de setembro de 1990. Brasília, 1991a.

. Lei Orgânica da Saúde n. 8.142, de 28 de dezembro de 1990. Brasília, 1991b.

Ministério da Saúde. Divisão de saúde do trabalhador. Relatório Final da $2^{a}$ Conferência Nacional de Saúde do Trabalhador. Brasília, 1994.

Portaria n. 1.679 - Renast, de 19 de setembro de 2002. Dispõe sobre a estruturação da Rede Nacional de Atenção Integral à Saúde do Trabalhador no SUS e dá outras providências. DOU n. 183, Seção I, 20 set. 2002. 
BRASIL. Secretaria de Atenção à Saúde. Departamento de Ações Programáticas Estratégicas. Área Técnica de Saúde do(a) Trabalhador(a) - Cosat. Política nacional de segurança e saúde do trabalhador. Brasília, nov. 2004.

. $3^{\text {a }}$ Conferência Nacional de saúde do trabalhador - Trabalhar sim, adoecer não - Textos de apoio. Coletânea, Brasília, n. 1, 2005.

BRAVO, Maria Inês Souza. Gestão democrática na saúde: o potencial dos conselhos. In: ; PEREIRA, P. A. P. Política social e democracia. São Paulo: Cortez, 2001. lia, 2004.

Política de saúde no governo Lula: algumas reflexões. Revista Inscrita, BrasíPolítica de saúde no governo Lula. In: et al. (Org.). Política de saúde na atual conjuntura: modelos de gestão e agenda para a saúde. Rio de Janeiro: Uerj, 2007.

; MATOS, Castro de. A saúde no Brasil: reforma sanitária e ofensiva neoliberal. In: ___ PEREIRA, Potyara A. P. (Orgs.). Política social e democracia. São Paulo: Cortez; Rio de Janeiro: Uerj, 2001.

Reforma sanitária e projeto ético-político do Serviço Social: elementos para debate. In: et al. Saúde e Serviço Social. São Paulo: Cortez; Rio de Janeiro: Uerj, 2004.

BRAZ, Marcelo. O governo Lula e o projeto ético-político do Serviço Social. Serviço Social \& Sociedade, São Paulo, n. 78, 2004.

O PAC e o Serviço Social: crescimento para quê e para quem? — os setenta anos da profissão e os seus desafios conjunturais. Serviço Social \& Sociedade, São Paulo, n. 91, 2007.

COSTA, Maria Dalva H. O trabalho nos serviços de saúde e a inserção dos assistentes sociais. Serviço Social \& Sociedade, São Paulo, n. 62, 2000.

DIAS, Elizabeth Costa; HOEFEL, Maria da Graça. O desafio de implementar as ações de saúde do trabalhador no SUS: a estratégia da Renast. Ciência \& Saúde Coletiva, v. 10, n. 4, p. 817-828, 2005.

FADEL DE VASCONCELOS, Luiz Carlos. Saúde, trabalho e desenvolvimento sustentável: apontamentos para uma política de Estado. 2007. Tese (Doutorado) — Escola Nacional de Saúde Pública Sérgio Arouca, Fiocruz, Rio de Janeiro 
FLEURY, Sonia. A seguridade inconclusa. In: INESC. A era FHC e o governo Lula: transição? Brasília: Inesc, 2004.

FREIRE, Lúcia M. B. O Serviço Social na reestruturação produtiva: espaços, programas e trabalho profissional. São Paulo: Cortez, 2003.

O Serviço Social e a saúde do trabalhador diante da reestruturação produtiva nas empresas. In: MOTA, Ana E. (Org.). A nova fábrica de consensos. São Paulo: Cortez, 1998.

GONÇALVES, Reinaldo. Lula: aposta perdida. Praia Vermelha: estudos de política e teoria social. Rio de Janeiro, 2003.

GRANEMANN, Sara. Fundações estatais: projeto de Estado do capital. In: BRAVO, M. I. S. et al. (Org.). Política de saúde na atual conjuntura: modelos de gestão e agenda para a saúde. Rio de Janeiro: Uerj, 2007.

IAMAMOTO, Marilda Villela. Serviço Social em tempo de capital fetiche: capital financeiro, trabalho e questão social. São Paulo: Cortez, 2007.

LACAZ, F. A. C. Saúde dos trabalhadores: cenário e desafios. Cadernos de Saúde Pública, Rio de Janeiro, v. 13, supl. 2, 1997.

Saúde do trabalhador: vinte anos de história e trajetória. In: BRASIL. $3^{\text {a Con- }}$ ferência Nacional de Saúde do Trabalhador, textos de apoio. Coletânea, Brasília: Conselho Nacional de Saúde, Ministério da Saúde/Ministério do Trabalho e Emprego/Ministério da Previdência Social, n. 1, 2005.

LESBAUPIN, Ivo. Governo Lula: um balanço do primeiro ano. Praia Vermelha: estudos de política e teoria social. Rio de Janeiro, 2003.

LEHER, Roberto. Fórum Social Mundial: uma combinação de espaço de catálise de movimentos com uma consistente agenda anti-imperialista. Revista Em Pauta, Rio de Janeiro, n. 19, 2007.

MATOS, Maurílio Castro de. O debate do Serviço Social na saúde na década de 90. Serviço Social \& Sociedade, São Paulo, n. 74, 2003.

Assessoria e consultoria: reflexões para o Serviço Social. In: BRAVO, M. I. S.; MATOS, M. C. de. Assessoria, consultoria \& Serviço Social. Rio de Janeiro: 7 Letras, 2006.

MENDES, Jussara Maria Rosa; WÜNSCH, Dolores Sanches. Formação em saúde do trabalhador. In: ENPESS - ENCONTRO NACIONAL DE PESQUISADORES EM SERVIÇO SOCIAL, 11. Anais eletrônicos. São Luís: Abepss, 2008. 
NETTO, José Paulo. Capitalismo monopolista e Serviço Social. São Paulo: Cortez, 1992.

. A construção do projeto ético-político do serviço social frente à crise contemporânea. In: Capacitação em Serviço Social e Política Social. Brasília: Cead/UnB, 1999. Módulo 1.

A conjuntura brasileira: o Serviço Social posto à prova. Serviço Social \& Sociedade, São Paulo, n. 79, 2004.

O movimento de reconceituação 40 anos depois. Serviço Social \& Sociedade, São Paulo, n. 84, 2005.

ORTIZ, Fátima da Silva Grave. O Serviço Social e sua imagem: avanços e continuidades de um processo em construção. 2007. Tese (Doutorado) — Escola de Serviço Social, Universidade Federal do Rio de Janeiro, Rio de Janeiro.

RODRIGUES, Mavi. Assistencialização da seguridade e do Serviço Social no Rio de Janeiro: notas críticas de um retrocesso. Serviço Social \& Sociedade, São Paulo, n. 91, 2007.

SADER, Emir et al. Governo Lula: decifrando o enigma. São Paulo: Viramundo, 2004.

SOARES, Laura Tavares. Os custos sociais do ajuste neoliberal na América Latina. São Paulo: Cortez, 2000. (Questões da Nossa Época, v. 78.)

SOUZA, Rodriane de Oliveira; BRAVO, Maria Inês Souza. Conselhos de Saúde e Serviço Social: luta política e trabalho profissional. Ser Social, Brasília, n. 10, 2002.

TAVARES SOARES, Laura. O Programa Fome Zero. In: SADER, Emir et al. Governo Lula: decifrando o enigma. São Paulo: Viramundo, 2004. 